\title{
Constitutive Modeling for Prediction of Optimal Process Parameters in Tribo-corrosion Inhibition of Steel Pipes Carrying Fracking Fluid
}

Jitendra narayan Panda ( $\sim$ jitendra.panda@ucalgary.ca )

University of Calgary https://orcid.org/0000-0003-4972-8046

Edwin Yanez Orquera

University of Calgary Schulich School of Engineering

Brandon Christopher Wong

University of Calgary Schulich School of Engineering

Philip Egberts

University of Calgary Schulich School of Engineering

\section{Research Article}

Keywords: tribocorrosion, corrosion inhibitor, friction and wear, RSM

Posted Date: March 1st, 2021

DOI: https://doi.org/10.21203/rs.3.rs-265319/v1

License: (c) (i) This work is licensed under a Creative Commons Attribution 4.0 International License. Read Full License 


\section{Abstract}

The present work examines the effect of three propriety corrosion inhibitors (Dynarate, DWP and CalGuard) on the tribo-corrosion behavior of AISI 4715 steels used to carry fracking liquid from their storage pool to the geological formation. The effect of these three additives on the wear and corrosion behavior of AISI 4715 steel was investigated using a reciprocating tribometer integrated with an open circuit potential electrochemical apparatus. Response Surface Methodology (RSM) was applied to statistically model the effects of various concentrations of Dynarate, DWP and

CalGuard on the average coefficient of friction (COF) between the steel and a sapphire counter surface, as well as the total wear loss of the steel due to the combined action of wear-corrosion and inhibition efficiency during sliding. The mathematical regression models were derived from the analysis of variance (ANOVA) techniques. Optimization of the individual variables to minimize the friction and wear responses was estimated using RSM. A full quadratic regression model was established and authenticated before the variables were optimized for different responses. The overall results revealed that Dynarate significantly decreased the COF (0.147) and wear rate $(0.3 \mathrm{~mm} / \mathrm{year})$ with an inhibition

efficiency of $480 \%$ at a concentration of $1 \%$. To investigate the effectiveness of the regression model at predicting

the wear rate, the samples were characterized using 3D optical prolometer and scanning probe microscopy to describe the effect of various additive on the surface morphology of steel. The surface topography measurements

indicated the worn regions for the samples where the Dynarate additive was used was smoother compared with those having the DWP and CalGuard additives. This observation was attributed to the formation of protective Im which limits the transfer of aggressive ions transfer to the steel surface and reduced the total wear loss due to wear and corrosion.

\section{Full Text}

This preprint is available for download as a PDF.

\section{Figures}




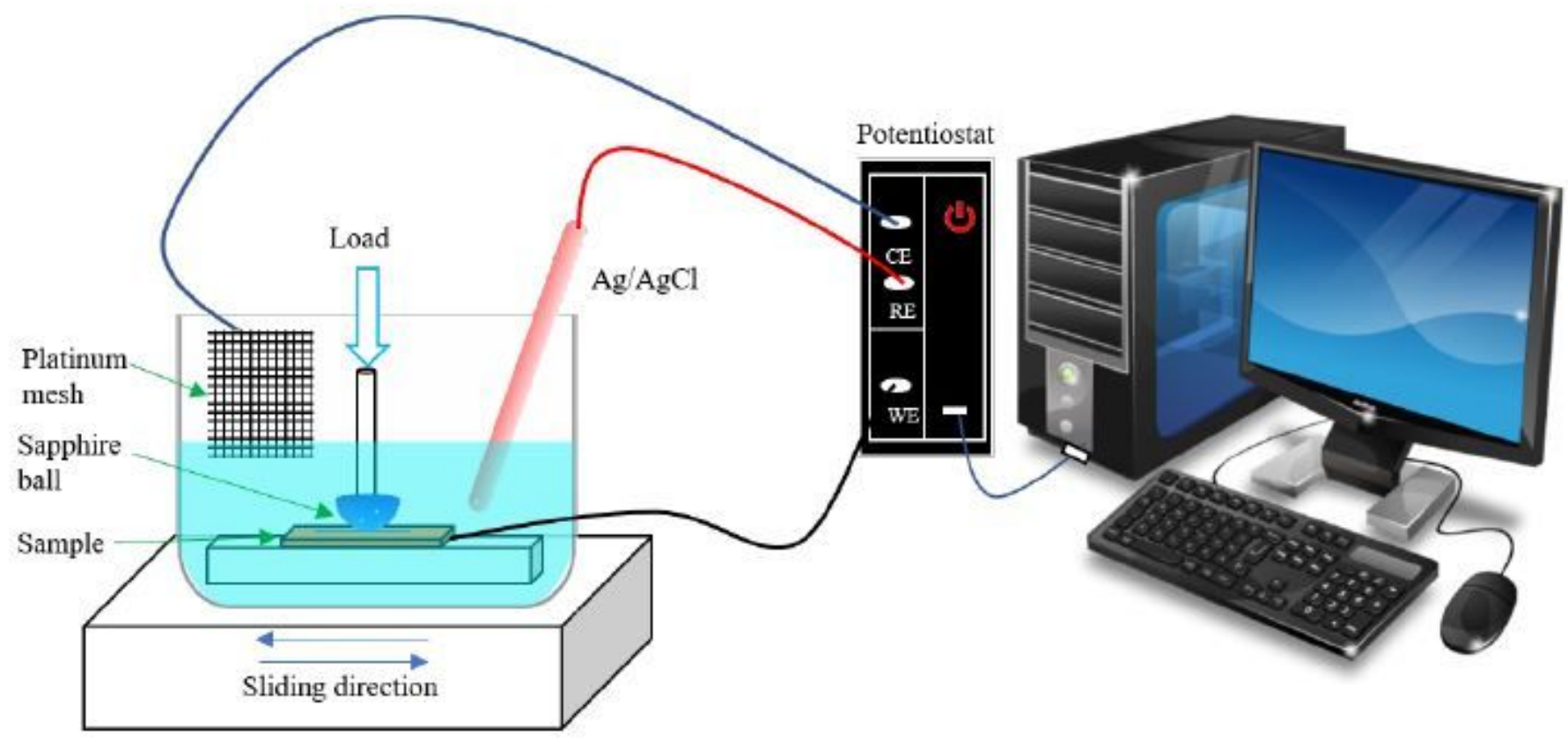

\section{Figure 1}

Design of the experimental set-up for a three-probe electrochemical cell combined with the reciprocating tribome ter.

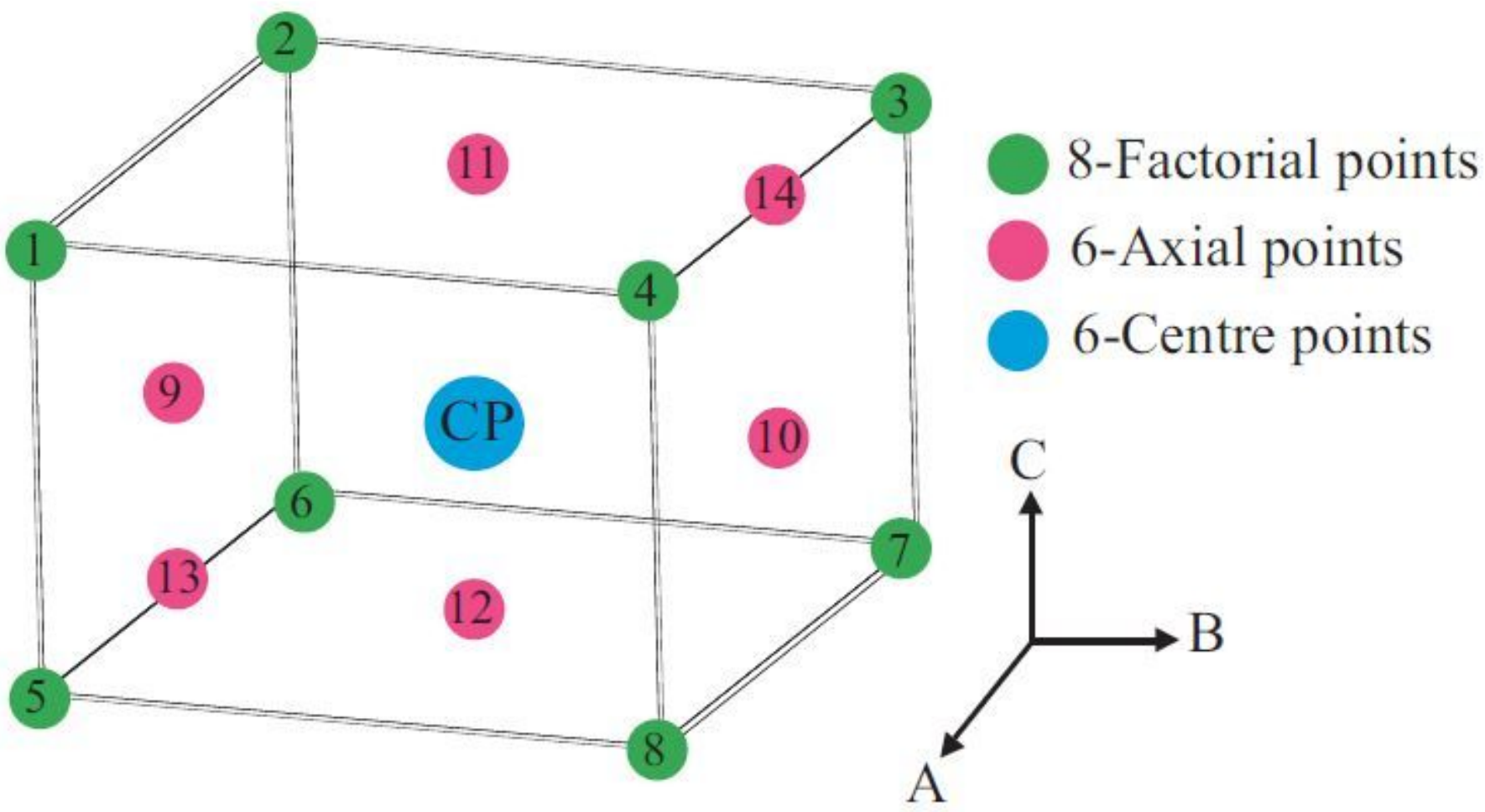

Figure 2

Arrangement of points for 23 factorial design. 


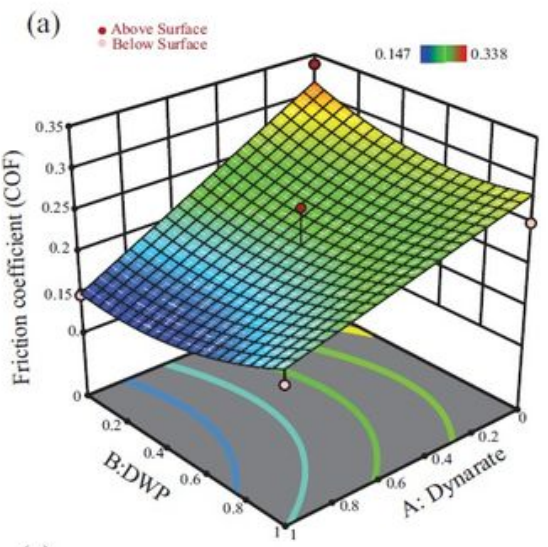

(b)

(c)
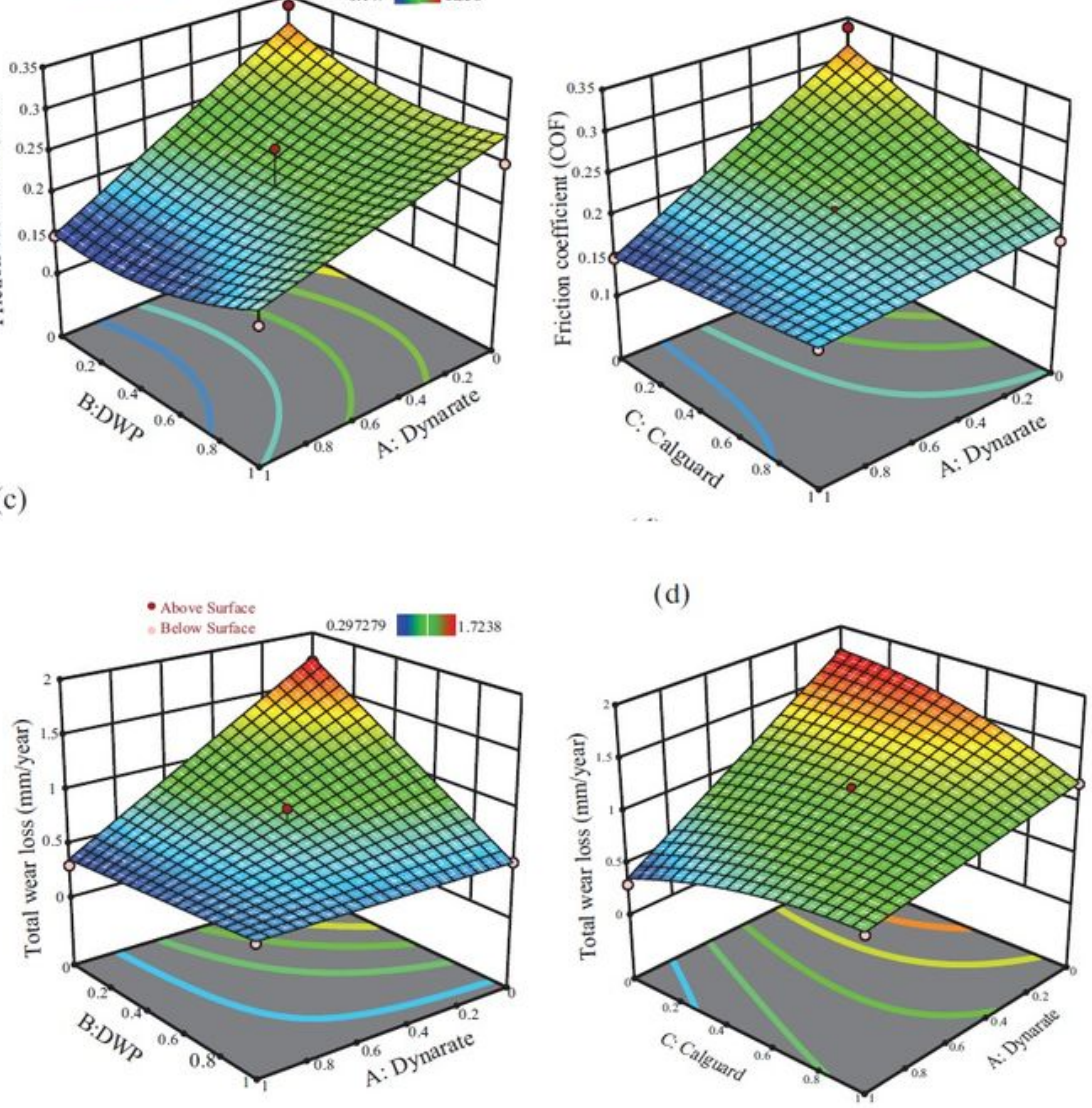

(e) Above Surface
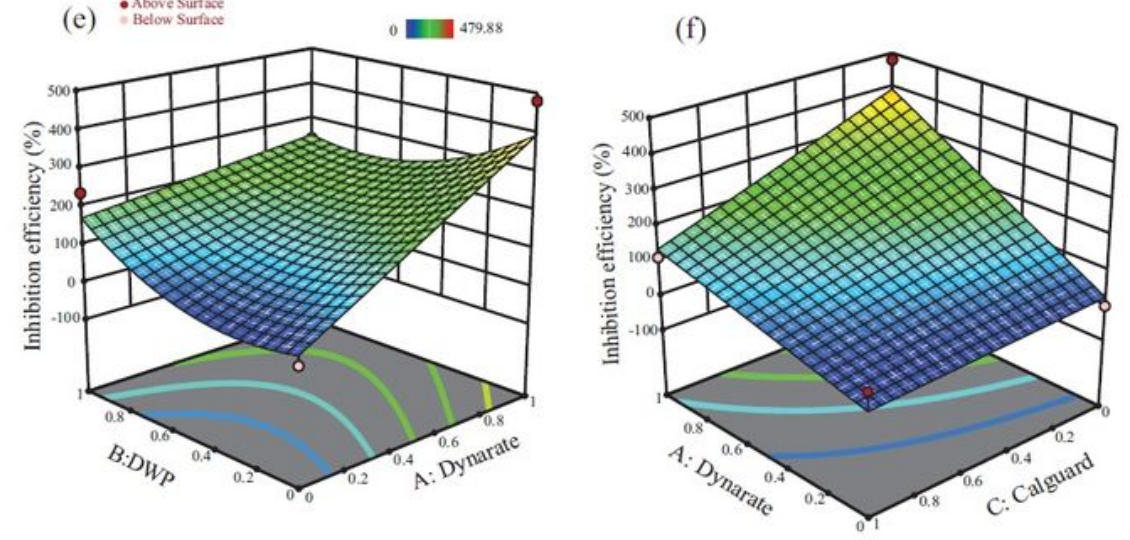

\section{Figure 3}

3D surface plots of (a-b) COF, (c-d)total wear loss, and (e-f) inhibition efficiency. In (a), (c), and (e), the concentration of CalGuard was constant and had a value of 0 vol\%. In (b), (d), and (f), the concentration of DWP was constant and had a value of 0 vol\%. 
(a)
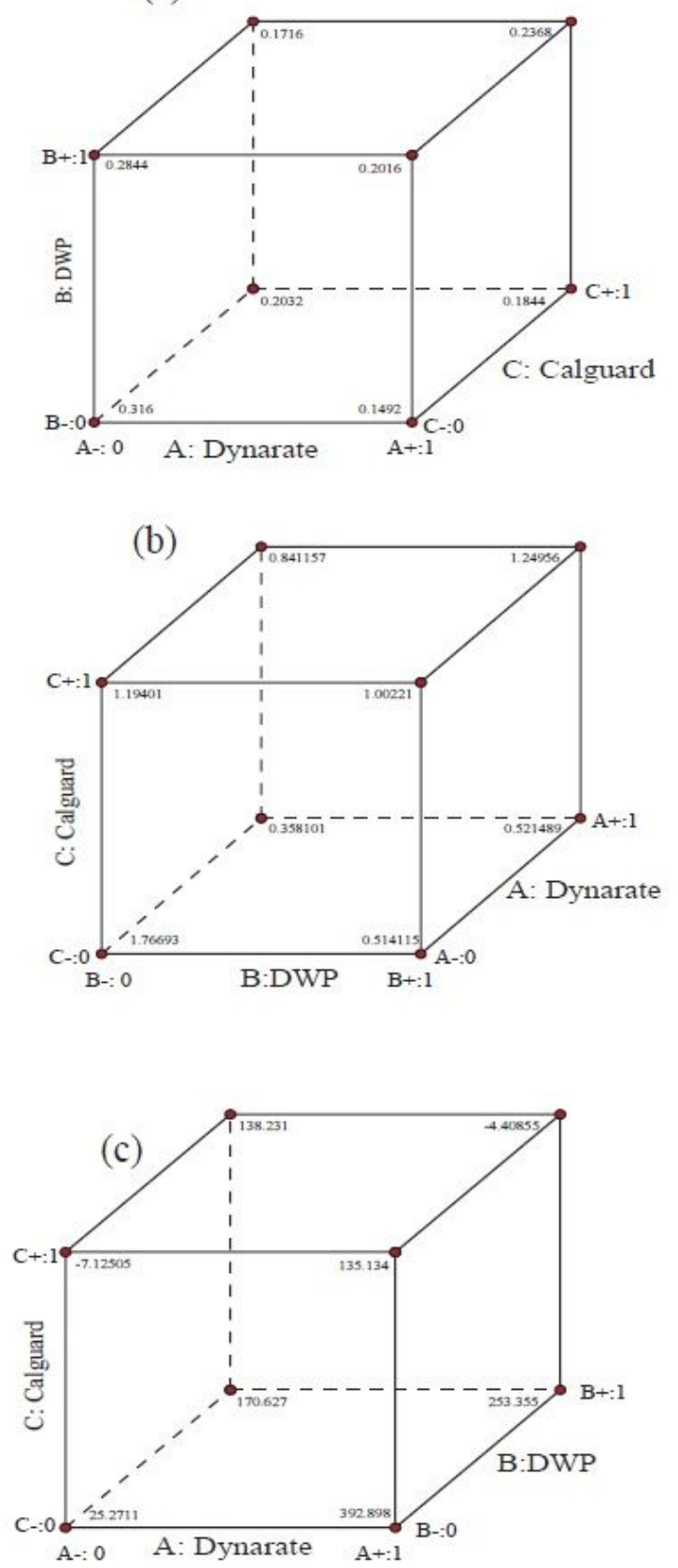

\section{Figure 4}

Cube plot of (a) COF, (b)total wear loss and (c) inhibition efficiency 
(a)

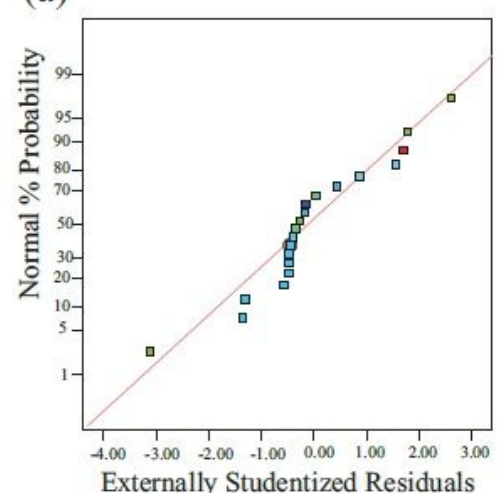

(d)

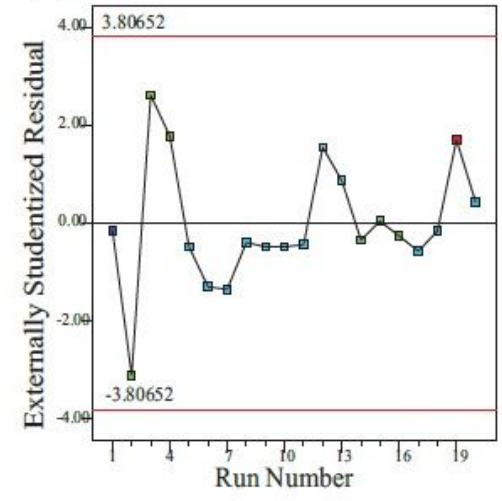

(g)

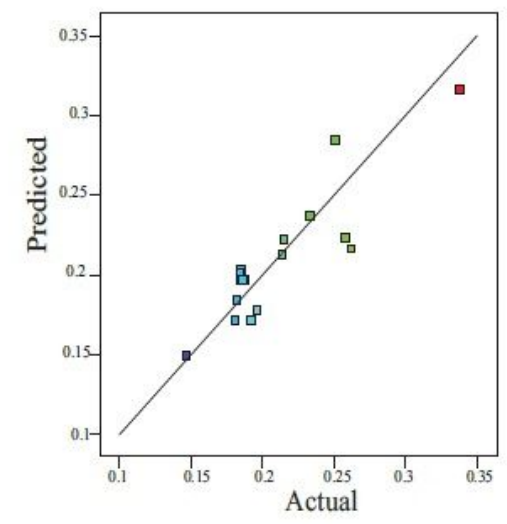

(b)

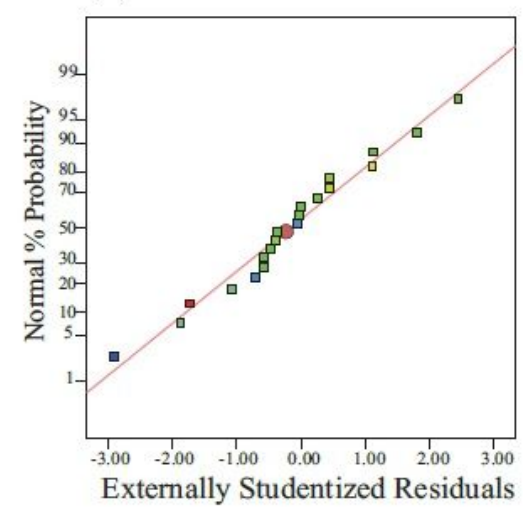

(e)

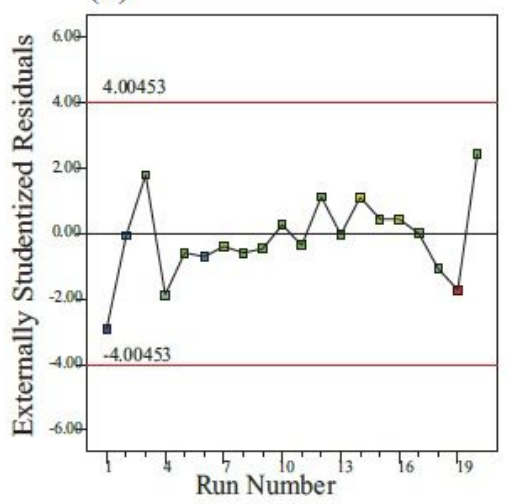

(h)

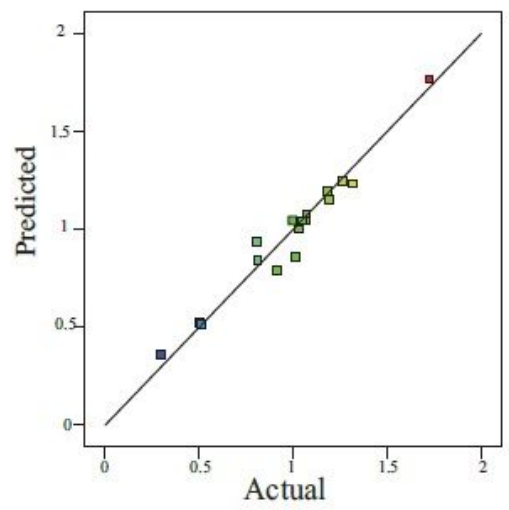

(c)

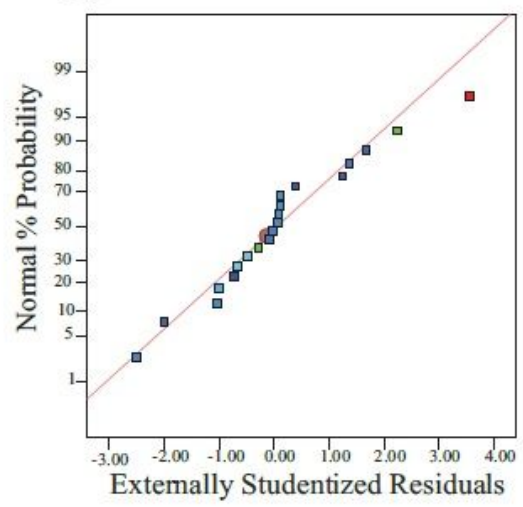

(f)

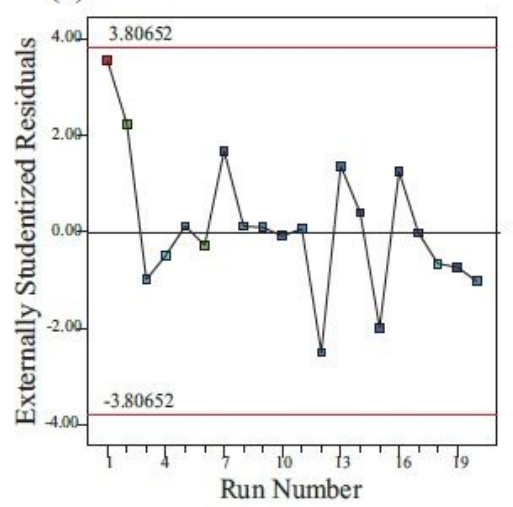

(i)

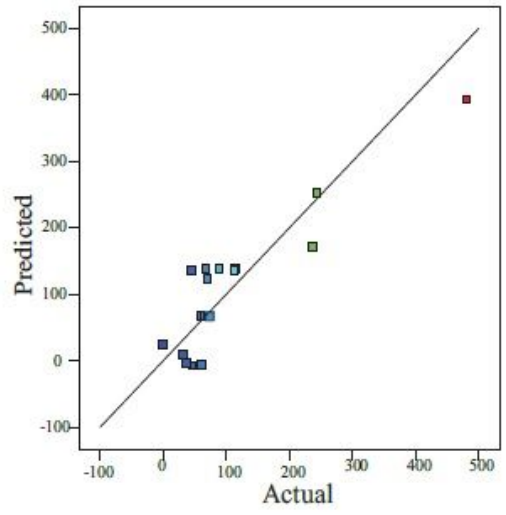

Figure 5

Data analysis plot of residuals vs probability, residuals vs run, predicted vs actual for $(a, d, g) C O F,(b, e, h)$ total wear loss, $(c, f, i)$ inhibition efficiency. 

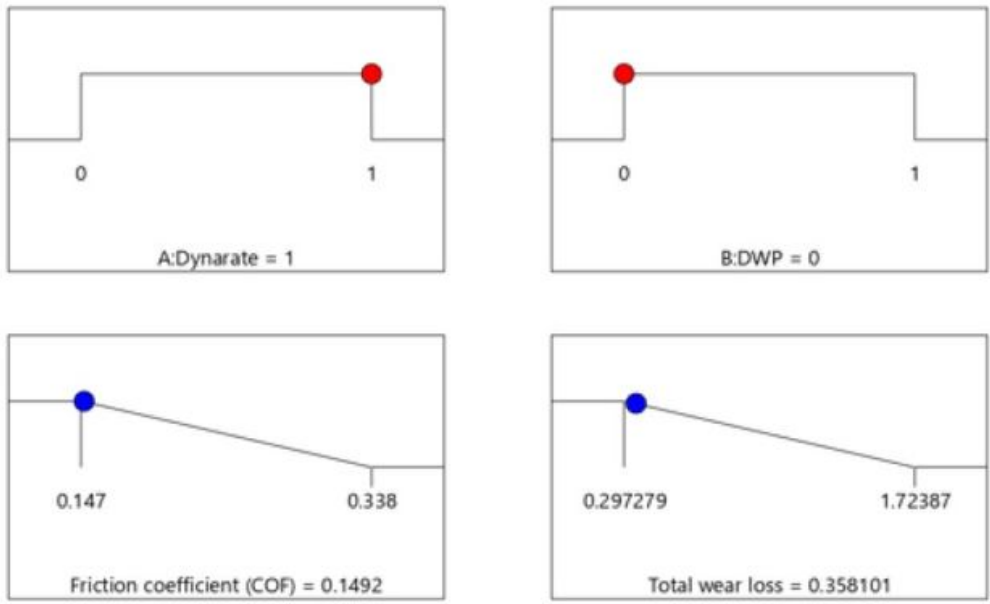
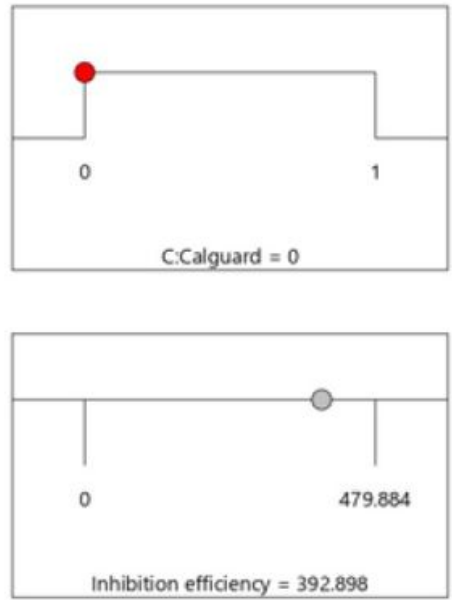

Desirability $=0.969$

Solution 1 out of 66

\section{Figure 6}

Numerical optimization of process variables. 


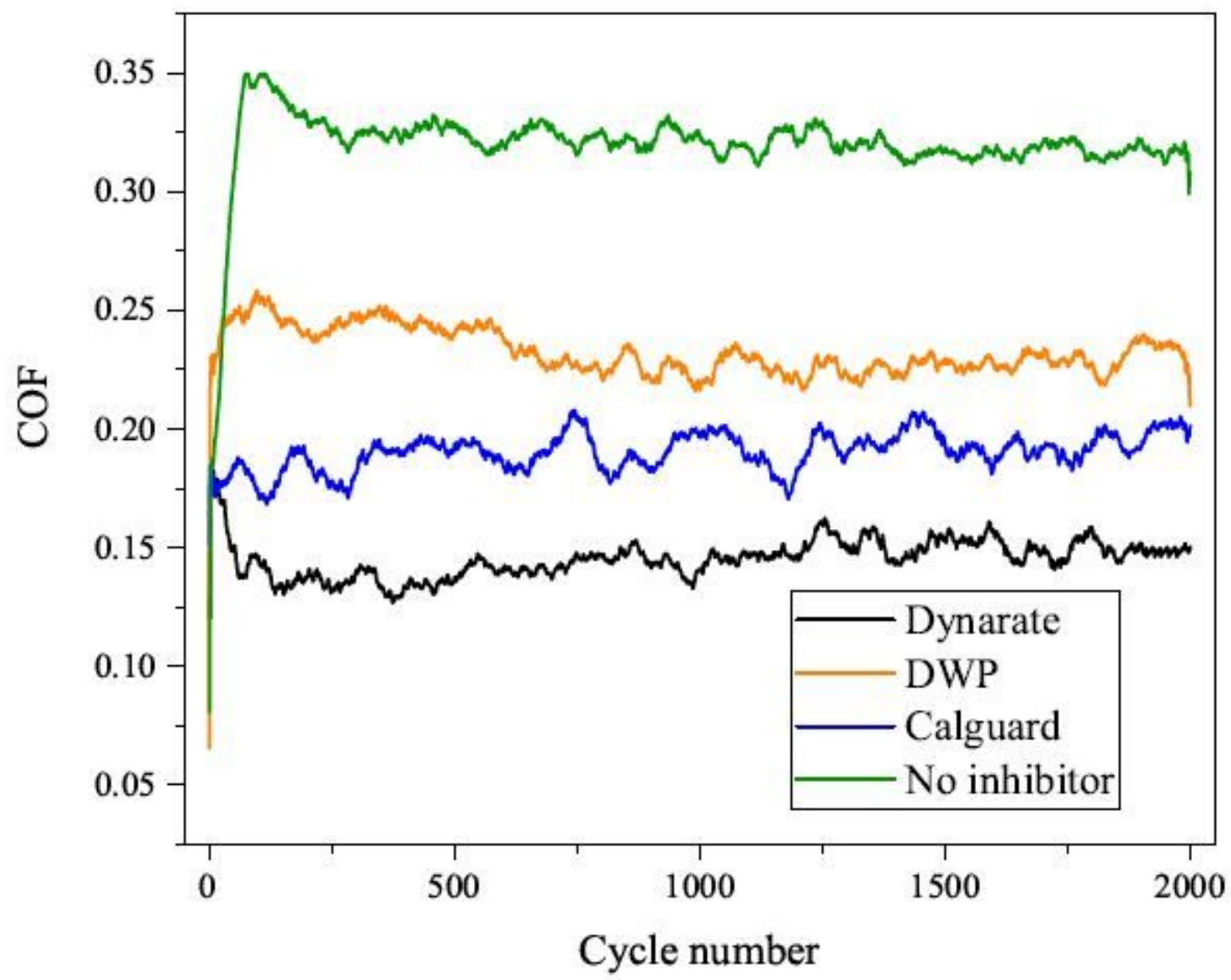

Figure 7

Friction coefficient versus cycle number of steel samples acquired under different additives (1\% concentration) at $10 \mathrm{~N}$ load and $6 \mathrm{~mm} / \mathrm{s}$ sliding velocity 


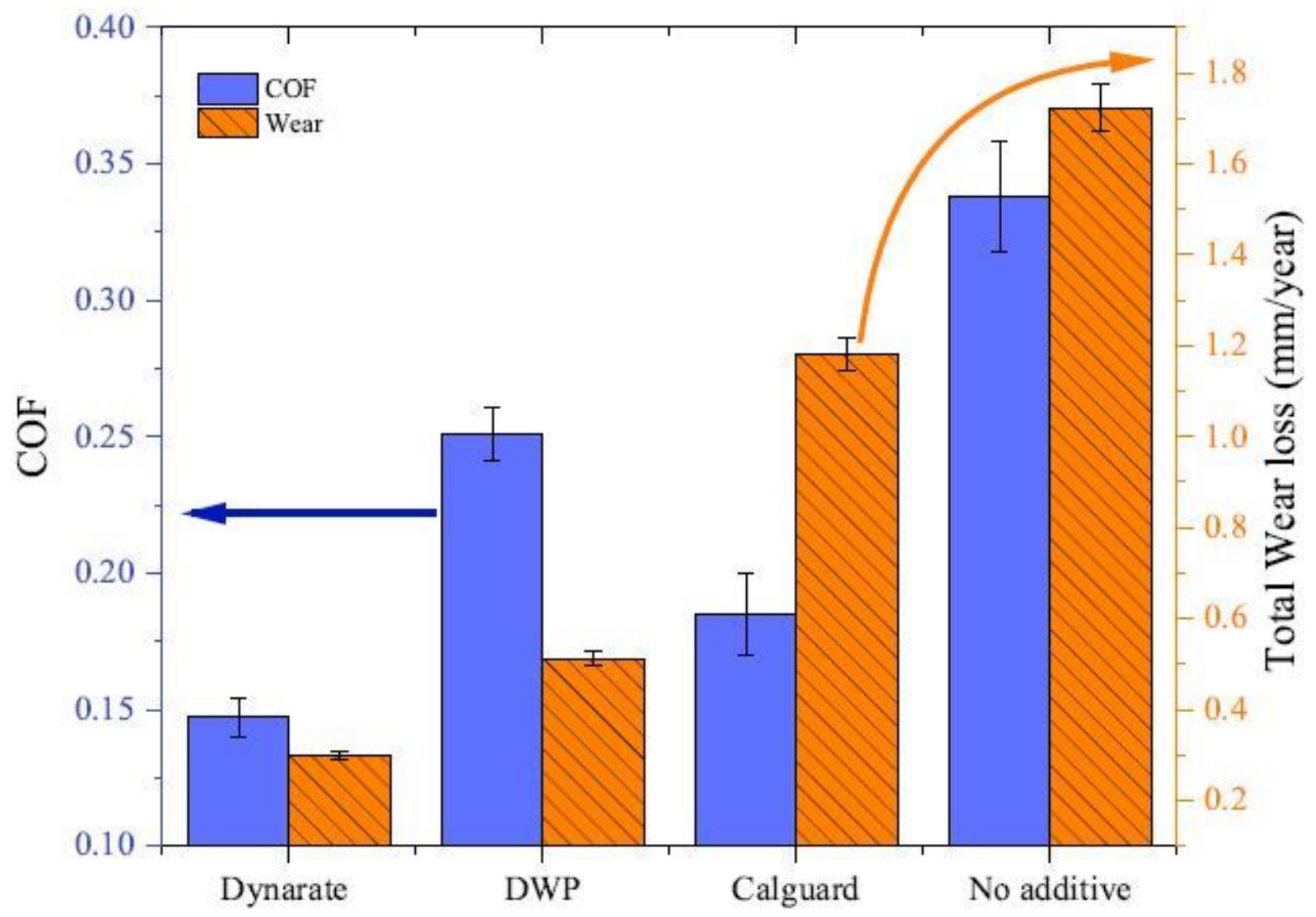

Figure 8

Variation of the COF and total wear loss under different additives, each added at 1 vol\% concentration to the hydraulic fracturing fluid. 


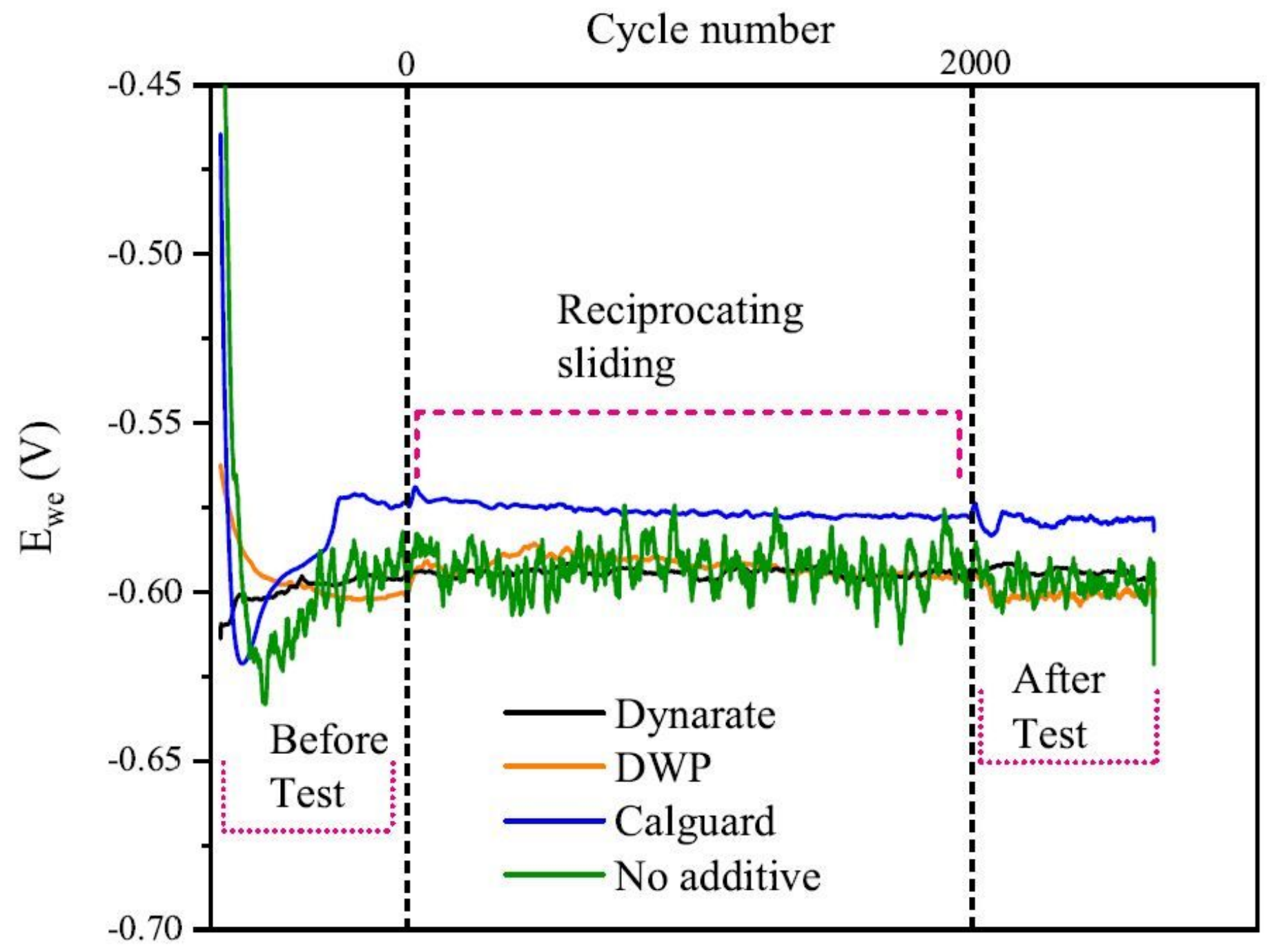

Figure 9

Working electrode potential (Ewe) vs test duration of the additives ( 1 vol\% concentration) under open circuit potential (OCP) at $10 \mathrm{~N}$ load, $6 \mathrm{~mm} / \mathrm{s}$ sliding velocity. 

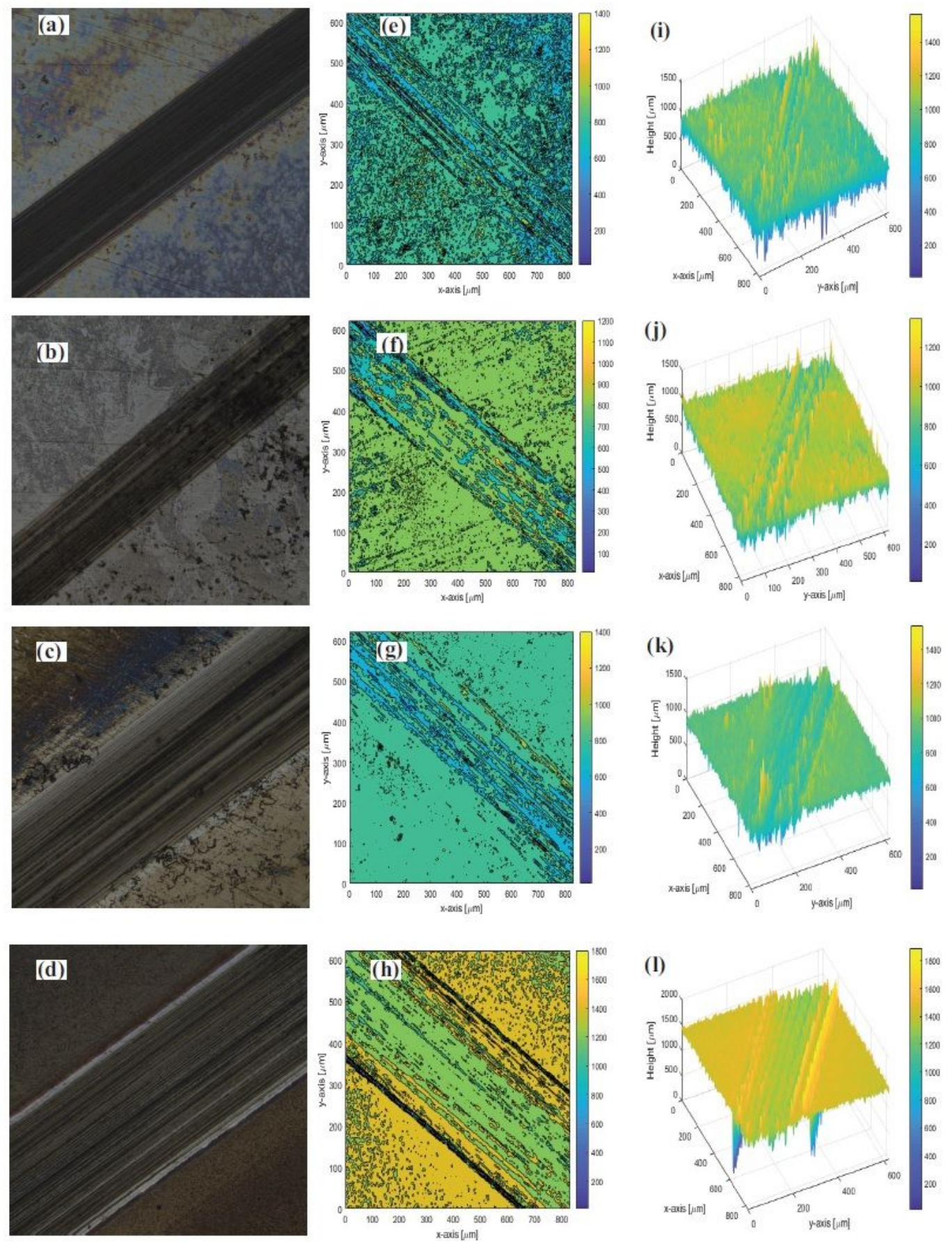

\section{Figure 10}

3D optical prolometer images (a-d) 2D worn surface, (e-h) 2D surface color plots, (i-l) 3D surface topography of the additives ( $1 \%$ concentration) $(a, e, i)$ Dynarate, $(b, f, j)$ DWP, $(c, g, k)$ CalGuard, $(d, h, l)$ No additive after the test 

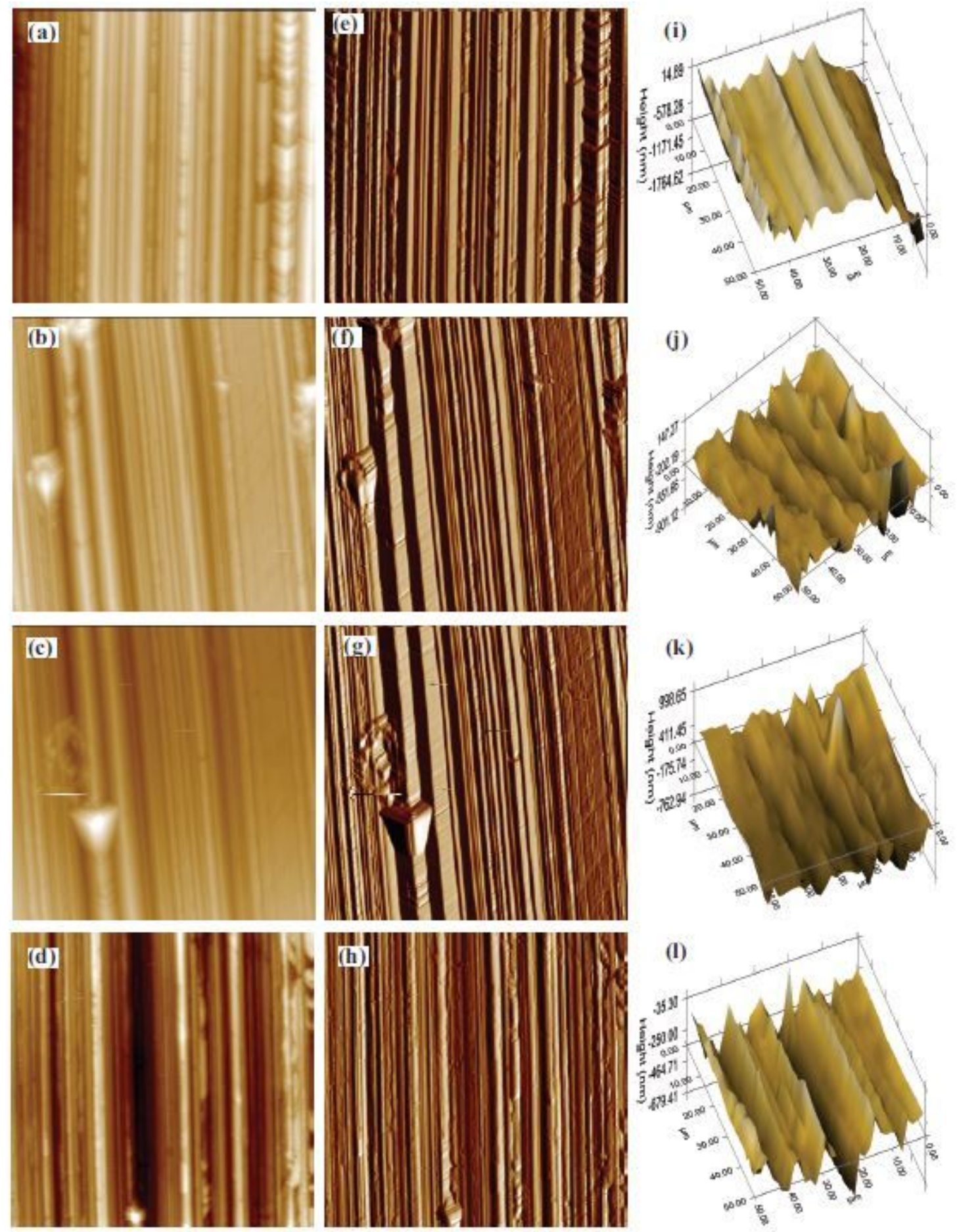

Figure 11

SPM images (a-d) 2D gradient, (e-h) 2D surface topography, (i-I) 3D surface topography of the additives ( $1 \%$ concentration) $(\mathrm{a}, \mathrm{e}, \mathrm{i})$ Dynarate, $(\mathrm{b}, \mathrm{f}, \mathrm{j})$ DWP, $(\mathrm{c}, \mathrm{g}, \mathrm{k})$ CalGuard, $(\mathrm{d}, \mathrm{h}, \mathrm{l})$ No additive after the test 